\title{
"Se não cuidarmos de nós, ninguém cuidará": Autoajuda financeira e racionalidade política neoliberal
}

"If We Don't Look after Ourselves, No One Will": Financial Self-help and

Neoliberal Political Rationality

"Si nous ne nous occupons pas de nous, personne ne le fera à notre place":

Auto-assistance financière et rationalité politique néolibérale

Fernando Ampudia de Haro

\section{OpenEdition}

Journals

Edição electrónica

URL: http://journals.openedition.org/rccs/5386

DOI: $10.4000 /$ rccs.5386

ISSN: 2182-7435

Editora

Centro de Estudos Sociais da Universidade de Coimbra

Edição impressa

Data de publição: 1 setembro 2013

Paginação: 111-134

ISSN: 0254-1106

Refêrencia eletrónica

Fernando Ampudia de Haro, «"Se não cuidarmos de nós, ninquém cuidará": Autoajuda financeira e racionalidade política neoliberal », Revista Crítica de Ciências Sociais [Online], 101 | 2013, posto online no dia 17 fevereiro 2014, consultado o 04 fevereiro 2021. URL: http://journals.openedition.org/rccs/ 5386 ; DOl: https://doi.org/10.4000/rccs.5386 


\section{"Se não cuidarmos de nós, ninguém cuidará": Autoajuda financeira e racionalidade política neoliberal}

O objetivo do presente artigo é analisar criticamente o discurso elaborado pela literatura de autoajuda financeira (LAF) no contexto geral do processo de financeirização. Esta análise utiliza como material empírico publicações próprias deste género disponíveis no mercado editorial português, desenvolvendo-se de acordo com a grelha teórica dos estudos sobre governamentalidade (governmentality studies) de inspiração foucaultiana. Na primeira secção é revisto o conceito de financeirização, apontando para as suas debilidades e forças teóricas e empíricas. A falta de atenção aos aspetos microssociológicos é precisamente uma das debilidades que justifica a necessidade de explorar, numa segunda secção, o tipo de subjetividade relacionada com o capitalismo financeirizado. A terceira secção analisa as dimensões centrais dessa subjetividade tal como é apresentada pela LAF, o que inclui um enquadramento das características destas publicações assim como o estudo do motivo, do objetivo e da forma de fazer aquilo que a autoajuda aconselha. A última secção centra-se na base social dos textos como ferramentas discursivas próprias de uma racionalidade política neoliberal.

Palavras-chave: autoajuda financeira; capitalismo financeiro; crédito ao consumidor; educação financeira; gestão financeira.

Falar hoje em dia em financeirização é falar na face dominante do capitalismo contemporâneo. Se aceitarmos, inicialmente, uma definição genérica, o conceito de financeirização designa o aumento constante e continuado dos mercados, atores, instituições e motivos financeiros como protagonistas da economia mundial (Epstein, 2005: 3). As abordagens do fenómeno da financeirização são, predominantemente, de natureza macroeconómica. Quando se pensa na colonização da economia pelas finanças é quase inevitável assumirmos a dimensão mundial do fenómeno, o que leva a focar a análise nas condições estruturais que contribuem para a extensão de um capitalismo progressivamente financeirizado: as grandes tendências e as forças da globalização, as políticas por blocos e áreas geográficas ou 
a ação de entidades nacionais e supranacionais de carácter político ou corporativo. No entanto, desde Max Weber, sabemos que o capitalismo pressupõe a existência de um espírito ou, segundo a terminologia sociológica, uma subjetividade. De facto, no âmbito da financeirização, este é um aspeto menos tangível e mais dificilmente identificável, embora não menos importante. $\mathrm{O}$ capitalismo financeirizado requere e alimenta uma maneira de ver e agir, um modo de perceber e interpretar o mundo e uma forma de autoperceção individual, que remete para um arquétipo humano de gestão comportamental e emocional, que simultaneamente produz e é produzido pelo próprio capitalismo financeiro.

Este artigo ocupa-se dessa subjetividade. Mais especificamente, o seu objetivo é analisar criticamente o discurso elaborado por uma das ferramentas de transmissão e de construção da subjetividade: a literatura de autoajuda financeira (LAF). Esta análise a) utiliza como material empírico publicações próprias deste género disponíveis no mercado editorial português; e b) é desenvolvida de acordo com a grelha teórica dos estudos sobre governamentalidade (governmentality studies) de inspiração foucaultiana. Através desta análise procura-se chamar a atenção para a importância de uma modalidade de subjetividade afim aos requisitos e às exigências do capitalismo financeirizado (Papalini, 2013), e que é funcionalmente apta para a sua manutenção e reprodução.

De acordo com este objetivo, o artigo apresenta uma primeira secção onde é revisto o conceito de financeirização apontando para as suas debilidades e fortalezas teóricas e empíricas. É precisamente uma das suas debilidades, a falta de atenção aos aspetos microssociológicos que justifica a necessidade de explorar, numa segunda secção, o tipo de subjetividade relacionada com o capitalismo financeirizado. A terceira secção analisa as dimensões centrais dessa subjetividade tal como é apresentada pela LAF, o que inclui um enquadramento das características destas publicações, assim como o estudo do motivo, do objetivo e da forma de fazer aquilo que a autoajuda aconselha. A última secção centra-se na base social dos textos como ferramentas discursivas próprias de uma racionalidade política neoliberal, entendido o neoliberalismo, tal como foi anteriormente referido, a partir do enfoque neofoucaultiano da governamentalidade.

\section{O(s) significado(s) da financeirização}

O termo financeirização é recente, o que explica que ainda estamos longe de uma definição unívoca e de consenso acerca das suas dimensões constitutivas. Contudo, é possível referir os aspetos que a literatura especializada aponta como consolidados e em relação aos quais existe relativo consenso: 
a) De forma genérica, o conceito remete para o predomínio do capital que circula pelos canais financeiros face ao que circula pelos canais da economia produtiva. Este predomínio é o resultado de um processo histórico que corresponde à passagem de um sistema fordista-produtivo a um pós-fordista-financeiro (Heilbron, 2005; Epstein, 2005).

b) Este predomínio implica uma mudança do equilíbrio entre os mercados financeiros e as corporações empresariais e industriais em favor dos primeiros, o que se traduz numa pressão dos dividendos sobre a política industrial a longo prazo (Langley, 2007).

c) A atividade financeira revela uma capacidade elevada para criar novos ativos e sistemas de indexação que podem funcionar como colaterais (Leyshon e Thrift, 2007).

d) Numa escala global, a economia aparece liderada pelas finanças, apoiadas estrutural e logisticamente nas tecnologias da informação e no processo de globalização económica (Martínez González-Tablas, 2012; Santos Ruesga, 2012).

Estamos, pois, perante alterações qualitativas e quantitativas associadas à atividade financeira. Neste contexto, há um conjunto relativamente homogéneo de manifestações e consequências relacionadas com o desenvolvimento do capitalismo financeirizado (Medialdea García e Sanabria Martín, 2013): o aumento da complexidade do mercado de divisas, as privatizações de empresas e serviços outrora públicos, a independência dos bancos centrais relativamente aos governos, a extensão do crédito nas mais diferentes modalidades, a utilização do emprego como variável de ajustamento ou o aprofundamento da instabilidade dos mercados financeiros.

Em síntese, a abordagem do fenómeno da financeirização apresenta características relativamente constantes quando considerada como objeto de estudo:

a) Constitui frequentemente aproximações macrossociológicas que outorgam prioridade explicativa à atuação dos governos, dos Estados e das corporações.

b) Apresenta-se como um processo com capacidade de imposição sobre os indivíduos, que agem como atores passivos ou como repositórios da ação do capitalismo financeiro.

c) Define-se, habitualmente, a partir de uma visão económica e, em consequência, através de variáveis cuja análise corresponderia, obviamente, à ciência económica.

O fenómeno parece estruturalmente bem identificado, sendo esta uma das suas forças. Força essa que constitui simultaneamente uma debilidade, já que os esforços analíticos têm sido concentrados nessas dimensões 
macrossociológicas, o que gera uma relativa ausência de estudos dedicados à concretização do fenómeno no quotidiano e na experiência imediata na vida das pessoas. Com o objetivo de colmatar esta lacuna, tem surgido a expressão "democratização das finanças" para referir, por um lado, a ampliação e o aprofundamento da participação nos mercados financeiros dos titulares de rendimentos médios e baixos e, por outro, para designar o leque de incentivos existentes para a aquisição de produtos financeiros com a finalidade de satisfazer necessidades como a habitação, a saúde, a educação ou a reforma (Erturk et al., 2007). Além da sua dimensão descritiva, a democratização das finanças também possui uma outra vertente com um acentuado cariz normativo, nomeadamente quando é vista como o resultado desejável de uma sociedade progressivamente orientada para o mercado. É o caso do mais recente laureado com o Prémio Nobel da Economia, Robert Shiller, que defende a ideia do desenvolvimento de produtos financeiros diversificados e abrangentes para um número vasto de clientes e para a satisfação das suas necessidades. Isto é, a democratização das finanças é entendida como extensão dos mercados financeiros, como via apetecível de acesso a serviços e bens básicos pelo facto de gerar um ordenamento social em que prevalece o princípio da livre escolha individual (Shiller, 2007). A manifestação mais visível desta visão normativa pode ser encontrada nos programas de educação financeira que, um pouco por todo lado, já foram ou estão a ser implementados. Países como Estados Unidos, Reino Unido ou Austrália são pioneiros neste terreno, muito embora Portugal já tenha o seu próprio Plano Nacional de Formação Financeira desde 2011 (CNSF, 2011). Transversalmente, este tipo de programas apoia-se na tentativa de melhorar quantitativa e qualitativamente os conhecimentos financeiros dos indivíduos, além de aumentar a sua capacidade para escolher entre diferentes produtos. Em suma, é o cliente quem monitoriza o mercado e obriga as instituições a ajustar a sua oferta segundo as necessidades de consumidores bem formados e informados (Bay et al., 2012).

Se recuperarmos a versão descritiva da democratização das finanças, é possível comprovar que a penetração do mundo financeiro no dia a dia, assim como o condicionamento das práticas quotidianas individuais e familiares, são dois aspetos hoje bem conhecidos (Martin, 2002; Erturk et al., 2005). Essa penetração também está presente na esfera do trabalho e das relações salariais (Alonso e Fernández Rodríguez, 2012) e na comunicação social, onde as finanças são várias vezes apresentadas de acordo com uma lógica de espetáculo e entretenimento (Harrington, 2008; Clark, Thrift e Tickett, 2004). Assim, esta aproximação às finanças integradas nas práticas quotidianas centra-se em aspetos microssociológicos e, de algum modo, 
revela os primeiros indícios daquilo que pode vir a ser a modalidade de subjetividade ligada a estas mesmas práticas.

\section{Subjetividade e finanças}

Como já foi apontado, o capitalismo financeirizado possui também o seu próprio espírito. Está ligado a um esquema de pensamento e representação do mundo e a um conjunto de padrões de regulação emocional e comportamental em constante interação com as práticas. Nesta linha, por exemplo, existem estudos que analisam a utilização de jogos de tabuleiro - o famoso "Cashflow" inspirado no best-seller Pai rico, pai pobre de Robert Kiyosaky - como ferramenta de educação, não só financeira, mas também vital, ou seja, uma ferramenta dirigida à aquisição de uma personalidade mais completa (Fridman, 2010). Outros estudos focam a sua atenção nos aspetos mentais e culturais das políticas de desenvolvimento das finanças pessoais (Aitken, 2007) ou nas mentalidades prototípicas dos investidores de acordo com o contexto histórico (Preda, 2005). Esta é uma linha de pesquisa na qual o presente trabalho procura incidir, pretendendo-se reforçar um conjunto de pontos fundamentais:

a) A construção de uma subjetividade afim ao processo de financeirização é imprescindível para a reprodução e manutenção desse processo. De facto, se este contribui para o desenvolvimento de um determinado tipo de subjetividade, simultaneamente, essa subjetividade alimenta e nutre tal processo.

b) Essa subjetividade não é estritamente o resultado de uma ação disciplinar que procura quebrar a vontade ou vencer as resistências do indivíduo. Sob uma perspetiva foucaultiana, é antes o produto de arranjos de diferentes tecnologias de governo, nomeadamente os discursos dos peritos, a regulamentação e a própria iniciativa dos indivíduos na aplicação de tecnologias de autogoverno (Miller e Rose, 1990).

c) Para a compreensão das dimensões subjetivas do fenómeno da financeirização é fundamental abandonarmos uma noção de poder como imposição unilateral procedente de alguma entidade central. Em troca, adotamos uma visão relacional desse mesmo poder, com origens diversas - estatais, corporativas, mercantis, etc. - e que conta com a autonomia individual como um facto a partir do qual governar. Qualquer exercício de configuração da subjetividade neste campo pressupõe uma noção de indivíduo autónomo. Portanto, se numa iniciativa como, por exemplo, o Plano Nacional de Formação Financeira identificamos claramente a procedência e a intencionalidade em organismos e agências formais de governo, no caso das publicações 
de autoajuda, essa identificação já não é tão linear. Apesar disso e como veremos, estas publicações são ferramentas relevantes na construção dessa subjetividade financeirizada. Estamos perante autores que, sem ligações profissionais ou partidárias com o aparelho estatal, oferecem através do mercado editorial um produto específico para a resolução de questões - endividamento, consumo, poupança, incerteza, entre outras - que foram previamente definidas como problemáticas.

d) A aparente trivialidade da literatura de autoajuda financeira como ferramenta de construção de subjetividades deverá ser desconstruída. No fundo, a sua análise, é uma tentativa de colocar o discurso no primeiro plano e analisar os conceitos, as explicações e as justificações que são mobilizadas em prol da legitimação de um modelo de conduta e de emocionalidade. Além da relação entre linguagem e política, relação esta que costuma oscilar entre a homologia e a ideologia, é necessário pensar numa outra abordagem que apresente uma visão dinâmica das relações entre o poder e o conhecimento. Sendo assim, a perspetiva foucaultiana destaca a necessidade de conhecer um objeto - no caso da LAF, o Eu, a personalidade ou a interioridade - para poder governá-lo: só quando esse objeto é convertido numa entidade cognoscível, calculável e administrável com as suas características e limites, é que adquire o estatuto de objeto suscetível de ser governado. Portanto, o estudo da subjetividade financeirizada não pode renunciar ao escrutínio dos discursos que moldam essa mesma subjetividade.

Tendo presentes estas diretrizes, iremos explorar a sua configuração tal como é apresentada nos textos de autoajuda financeira. Em resumo, porque deve o indivíduo ser financeiramente competente, o que é ser financeiramente competente e como sê-lo em termos técnicos, vitais e comportamentais.

\section{A literatura de autoajuda financeira (LAF): caracterização e apresentação} Inicialmente, a LAF pode ser identificada como um subtipo dentro do campo geral da literatura de autoajuda. Este tipo de literatura constrói programas de regulação comportamental e emocional de carácter reflexivo, conducentes a uma hipotética melhoria das condições psíquicas do indivíduo e à sua adaptação adequada ao contexto social em que vive. Tais programas constituem uma referência para a orientação do comportamento e da afetividade, circunstância que permite a integração do indivíduo nos padrões de atuação específicos do seu meio social. Como género, a literatura de autoajuda centra-se, globalmente, na dimensão 
subjetiva da pessoa: é este o ponto de arranque a partir do qual se persegue uma mudança vital que seja considerada satisfatória pelo indivíduo. Assim, a autoajuda serve-se de diferentes recursos retóricos, sendo os mais frequentes a) a utilização do "tu" ou do "nós" inclusivo; b) a repetição redundante das ideias principais; c) a exemplificação a partir de situações reais e testemunhos pessoais; d) o diagnóstico interativo mediante testes e provas e, e) a atribuição ao leitor da capacidade para modificar as suas condições comportamentais e emocionais. Por outro lado, a estrutura expositiva mais habitual remete, inicialmente, para a tipificação do problema ou da situação que se tenciona modificar para, posteriormente, aplicar as prescrições e soluções de acordo com o discurso legitimador que as justifica. ${ }^{1}$ Apesar de tudo, as fronteiras do género não são impermeáveis, o que explica a existência de um espaço relativamente difuso no qual se localizam publicações que, embora não possuam todas as características paradigmáticas da literatura de autoajuda, partilham com ela certos elementos e afinidades. Neste espaço podemos encontrar romances, biografias, memórias, textos de pensamento oriental, medicinas alternativas ou controlo corporal.

A temática das finanças pessoais é apenas uma das temáticas que costumam ser abordadas pela literatura de autoajuda. $\mathrm{O}$ texto seminal que cunhou o termo, Self-Help, de Samuel Smiles, publicado em 1875, já inclui conteúdos relativos à poupança. Trata-se de conselhos destinados aos pequenos aforradores, cujas iniciativas como modestos capitalistas são vistas como aquelas que realmente promovem a civilização e o desenvolvimento (Smiles, 1908[1875]: 341-368). Outros clássicos do género como Dale Carnegie - How to Win Friends and Influence People (1936) - ou Orison Sweet Marden - Be Good to Yourself (1910) - também incluem conteúdos nesta área, que estará presente nos manuais estabelecendo paralelismos entre o crescimento psíquico individual e a iniciativa particular para os negócios. A sua visibilidade aumenta durante as décadas do desenvolvimentismo europeu, o que provoca a inclusão de conteúdos relacionados com a gestão corporativa, a administração, os recursos humanos e o management emocional (Ampudia de Haro, 2010, 2011).

Atualmente, essa visibilidade não é menor. A crise económico-financeira que deflagrou em 2008, e as consequentes políticas de austeridade, dão forma a um quadro social no qual, mais do que nunca, adquire importância a questão das finanças pessoais. De facto, essa mesma relevância, quer seja real quer induzida, encontra-se associada a um discurso público que converte a noção de bancarrota na ameaça principal para a ordem social

\footnotetext{
${ }^{1}$ A melhor e mais completa caracterização do género pode ser consultada em Papalini (2008). Para uma versão mais breve, ver Papalini (2010).
} 
(Ampudia de Haro, 2014). Este contexto tem aberto uma janela de oportunidade comercial para a indústria editorial, circunstância que tem provocado uma proliferação de publicações que oferecem soluções ou procedimentos individualizados para as questões financeiras com o propósito de alcançar a transformação pessoal. Como tal, livrarias, aeroportos, grandes superfícies comerciais ou áreas de serviço em autoestradas são o 'habitat' frequente destas publicações. Além das características gerais próprias do género, a autoajuda financeira que hoje é publicada apresenta certas especificidades que convém assinalar:

a) O desdobramento reflexivo do indivíduo como objeto e sujeito da ajuda aplica-se prioritariamente a assuntos de natureza económico-financeira, nomeadamente à gestão do orçamento doméstico e ao planeamento da poupança e do investimento.

b) Não são manuais técnicos nem guias de divulgação de conhecimento económico. A vertente financeira é indissociável de um projeto mais amplo de mudança comportamental e emocional que é suposto ser operada através da ação financeira. A literatura de autoajuda financeira, em geral, não é apenas uma fonte de conhecimento, mas também e sobretudo, é uma fonte de mudança pessoal.

c) A justificação da sua pertinência, de acordo com os autores, baseia-se na sua categorização como instrumento para lidar com a crise. Esta categorização explica o facto de os textos incluírem algum tipo de abordagem à situação económica do país que justificaria o imperativo de recorrer à autoajuda financeira.

d) A autolegitimação dos autores realiza-se em função da sua condição de peritos em finanças ou da experiência profissional acumulada no campo económico como especialistas ou jornalistas.

e) A dialética das publicações é dupla: se por um lado, é evidente a intenção de incutir um modelo de autorregulação financeira e, nesta vertente, estas publicações possuem um potencial de criação de algo novo, por outro lado, ilustram e são porta-vozes desses modelos de autorregulação que já circulam previamente, tendo por isso capacidade para refletir padrões de comportamento existentes.

Qualquer seleção é, em último caso, arbitrária. Existem livros diferentes daqueles que aqui serão analisados que, no entanto, apresentam as mesmas características. Assim, os autores e os títulos poderiam ser outros que não aqueles aqui selecionados, sendo que, o tipo de discurso não seria substancialmente diferente. A escolha das publicações não está submetida a uma lógica de representatividade probabilística uma vez que não procura reproduzir o universo-alvo de estudo, ou seja, todos os livros de autoajuda 
financeira existentes no mercado. O tipo de representatividade que se procura aqui abordar é estrutural, isto é, procura-se analisar os discursos mais significativos produzidos desde o âmbito da LAF, ou aqueles mais frequentes quando a questão das finanças pessoais é abordada (Ibáñez, 1985). Fazendo emergir as linhas mestras do discurso estamos em condições de analisar criticamente o modelo de subjetividade que se propõe para, posteriormente, procedermos à sua interpretação teórica.

\section{Apresentação dos textos}

Os textos com base nos quais irá ser realizada a análise são os seguintes:

a) Como salvar a minha reforma (2011), de David Almas e Joaquim Madrinha. Os autores são jornalistas especializados em economia, com formação superior em finanças e negócios online. O livro aborda o tema das finanças pessoais no contexto da crise do sistema da Segurança Social, o que explicaria a necessidade de as pessoas optarem por sistemas privados de poupança-reforma para garantir a sua sobrevivência na reforma. De acordo com o ranking de "Livros de Gestão" do Diário Económico, a obra manteve-se entre as dez mais vendidas no período de abril a junho de 2011.

b) Seja mais esperto do que a crise (2009), de Luís Ferreira Lopes. O autor possui uma ampla trajetória dentro do jornalismo, mais especificamente, na vertente da informação económica. Atualmente, é editor de economia do canal SIC Notícias. Conta, aliás, com um prólogo de renome da autoria de Marcelo Rebelo de Sousa, que defende a pertinência da obra num contexto como o atual. É um texto focado nas práticas de poupança quotidiana, nos pequenos gestos que no dia a dia permitem ganhos significativos quando considerados a longo prazo.

c) $O$ seu primeiro milhão. Como poupar e fazer crescer o seu dinheiro (2013), de Pedro Queiroga Carrilho. Como diz a capa, esta é uma edição "anticrise". O autor é fundador da Kash Finanças Pessoais, empresa pioneira em formação financeira em Portugal. O livro, com um título tão comercialmente apelativo como clássico no terreno da autoajuda, relaciona a questão da poupança com a do investimento, concebidas ambas as atividades como faces da mesma moeda e devendo servir um propósito global de mudança vital.

d) Como esticar o salário e encurtar o mês (2009), de Camilo Lourenço. Mais um caso de um jornalista especializado em economia e finanças. Muito do que aparece neste livro faz parte dos seus comentários em programas de rádio e televisão como "Moneybox" ou "A cor do 
dinheiro". De novo, um amplo leque de sugestões e conselhos para poupar no dia a dia e, em menor medida, para transformar essa poupança em rendimentos futuros através do investimento.

e) O que os ricos sabem e não contam. Manual de Finanças para mudar a sua vida (2008), de Aitor Zárate. O autor, especialista em fiscalidade internacional e no mercado de futuros de Chicago, oferece um compêndio do seu conhecimento pessoal em investimento e poupança como método para uma mudança de vida. Ao contrário dos anteriores, o autor não adota um estilo expositivo clássico e escolhe um formato narrativo-dialogado com duas personagens principais: Roberto, que tem um método pessoal de enriquecimento, e José, o aluno que deseja conhecer esse método. A obra é um exemplo perfeito do carácter transnacional, transtextual e transcomercial da LAF. Originalmente publicado em espanhol, já conta com sete edições no país vizinho. O título original, Cambio de vida. Cómo me bice rico, não é mantido na tradução portuguesa, uma vez que a editora escolheu como título uma adaptação do clássico de Brian Sher, What Rich People Know and Desperately Want to Keep a Secret, de 2001, e publica-o com a capa da sua edição brasileira: O que os ricos sabem e não contam.

f) Vacas magras, porcos gordos. Manual de boas práticas para conservar e fazer crescer o seu dinheiro (2011), de José Manuel Malarmey Ribeiro. Conta com a introdução do Diretor-Geral da Liberty Seguros em Portugal, que justifica a obrigatoriedade do livro num país de "cigarras e formigas". O autor elabora uma obra focada, essencialmente, na questão da poupança quotidiana e na sua relação com o investimento, de forma a garantir segurança financeira no futuro.

\section{Os conteúdos da autoajuda financeira}

\subsection{O diagnóstico da LAF: as deficiências cognitivas e éticas dos portugueses}

O discurso da LAF inicia-se com uma contextualização social que justifica a sua própria existência como discurso e oferece uma explicação global dos fatores que explicam a crise portuguesa. Estes fatores são dois e encontram-se interligados - consumismo e endividamento - e apresentam uma dimensão particular e nacional. Particular, porque as deficiências ou as limitações cognitivas e éticas dos portugueses no terreno do consumo e do crédito são imputáveis a indivíduos específicos. Nacional, porque quando essas condutas particulares se agregam, o resultado é um país sobreendividado. Neste ponto, a soma das partes, ou seja, dessas condutas individuais financeiramente desregradas, é exatamente igual ao todo: uma nação em dificuldades. 
Comecemos pelas deficiências éticas. "Desde os Descobrimentos, há 500 anos que os Portugueses vivem acima das suas reais possibilidades" (Lopes, 2009: 74). Portugal é um país que teria desenvolvido um padrão de ostentação anómalo exibindo bens e condutas que não são próprios da sua condição material real. Antes, foram os barcos cheios de especiarias que mascaravam o sabor dos alimentos, o "exibicionismo pacóvio" (ibidem: 73) que criticava Eça de Queiroz ou o "pato bravo" da construção após o 25 de abril. Com a entrada no euro, o país voltou a insistir nesse padrão de ostentação com uma "[...] corrida ao endividamento numa altura em que os juros estavam historicamente baixos" (ibidem). Eis o "Homus (sic) Lusitanus", com a sua "[...] mania das grandezas, sobretudo das classes média e média-baixa” (ibidem: 123). Este 'Homo' concretiza-se num tipo ideal mais facilmente reconhecível para o leitor: "[...] o exemplo clássico da família Santos" (ibidem). Esta família, que representaria a situação mais corrente em qualquer família portuguesa de classe média, vive num ciclo de consumo, crédito e endividamento:

O casal está a pagar o empréstimo de dois carros, além da prestação da casa. Depois, meteram-se no empréstimo para o televisor novo [...] A seguir, os filhos não paravam de pedir a Playstation ou a Wii. Na cozinha, lá vieram as máquinas novas de lavar roupa e loiça, além do frigorífico combinado. Ah, estava a esquecer-me daquelas férias do outro lado do Atlântico. Tudo isto, a um juro que é melhor nem descrever. (ibidem: 128)

A metáfora recorrente para descrever este fenómeno é a da cigarra e a formiga, ilustrativa das "[...] raízes dos problemas auto-infligidos com que hoje nos deparamos" (Sousa in Ribeiro, 2011: 10), problemas ligados “[...] às ilusões do crédito fácil" (Lopes, 2009: 20) ou à paixão pelas compras na passagem de uma cultura de poupança tradicional para uma cultura do consumo (Lourenço, 2009: 40). O tipo ideal que representa essa cultura tradicional seria o Sr. Manuel,

[...] que mora no fim da nossa rua, que compra e consome apenas o que precisa e que tem hábitos de poupança muito sérios [...] não é uma pessoa vestida pelas melhores marcas ou que utilize um telemóvel de última geração; para não falar naquele automóvel em que ele anda e no sapateiro onde ele conserta o seu calçado. (Ribeiro, 2011: 17)

Em síntese, a sedução do consumo produziu níveis consideráveis de temeridade financeira, falta de visão a longo prazo e uma renúncia a adiar 
a gratificação (Carrilho, 2013: 40), dando origem à irresponsabilidade financeira em termos coletivos.

Para além das deficiências éticas, as cognitivas também explicam uma parte dessa irresponsabilidade. Estas deficiências cognitivas têm a ver com o baixo nível de literacia financeira dos portugueses e com as lacunas de conhecimentos sobre o dinheiro.

Um outro exemplo tido como prototípico contribui para ilustrar esta ideia. Camilo Lourenço apresenta o caso da Sra. Maria. Esta solicita um empréstimo para pagar a totalidade de um carro novo. Sabe que as prestações são de 300 euros mas só depois é que descobre que os juros são de $17 \%$ e que desistir, depois de ter assinado, acarreta penalizações: "O que é que o caso da Sra. Maria retrata? A falta de cultura financeira do português médio: as pessoas não fazem contas e não pensam no impacto das suas decisões no médio e no longo prazo. Estão apenas preocupadas em usufruir certo bem ou serviço" (Lourenço, 2009: 44). A iliteracia financeira corrige-se com a educação financeira. O objetivo seria interpretar adequadamente o dinheiro ou, por outras palavras, "[...] impedir que a inconsciência e a falta de respeito pelo dinheiro, e pelo seu valor intrínseco, se perpetuem nas gerações futuras" (Sousa in Ribeiro, 2011: 12). Sendo assim, e uma vez constatadas tais deficiências, abre-se o processo segundo o qual o indivíduo vai procurar "auto ajudar-se" financeiramente: dá início à aprendizagem da responsabilidade financeira que será, também, um caminho de transformação pessoal.

\subsection{Quem sou em termos financeiros?}

Como corresponde a qualquer exercício habitual no terreno da autoajuda, esse "auto ajudar-se" diz respeito às questões que cada pessoa deve colocar a si própria, não sendo apenas uma iniciativa para conhecer o estado das finanças pessoais. É, sobretudo, uma atitude abrangente que interroga o $\mathrm{Eu}$, pois é esse Eu que determina a gestão individual do dinheiro. O conhecimento do próprio estado financeiro é um modo de acesso ao autoconhecimento. Desta forma, os aspetos técnicos das finanças são indissociáveis da dimensão psicológica do indivíduo. Contudo, dependendo dos autores dos livros de autoajuda encontramos uma maior ou menor tendência para salientar explicitamente essa ligação. A técnica do autoconhecimento é reconhecida como imprescindível, mesmo quando é negada pelo autor a condição de texto de autoajuda:

Isto não é um daqueles livros de auto-ajuda mais ou menos esotéricos, mas é importante passar por esta fase das perguntas para nos darmos conta do tamanho das nossas 
dívidas e das necessidades que temos de mudar os padrões de consumo ou estilos de vida. (Lopes, 2009: 157)

De facto, existem várias perguntas às quais é preciso responder. Assim, a pessoa perguntar-se-á se tem ou não consciência da inflação, da realização de investimentos e compras emocionais, da tendência ao refinanciamento das dívidas mediante novos empréstimos (ibidem: 158), ou da possibilidade de estruturar as contas mediante a orçamentação das despesas e das receitas (Ribeiro, 2011: 13; Lourenço, 2009: 23) para, posteriormente, ser sincera consigo própria. Um passo mais à frente na prática do autoquestionamento conduz a pessoa a interrogar-se sobre as finanças como manifestação do seu $\mathrm{Eu}$, da sua interioridade, daquilo que determina a sua originalidade e autenticidade como indivíduo. $\mathrm{O}$ autoconhecimento permite fixar os fatores que dependem do controlo individual e, consequentemente, eliminar da equação aqueles que escapam a esse controlo. O indivíduo apresenta uma dualidade interioridade-exterioridade que determina uma solução clássica no campo da autoajuda: afastarmo-nos "[...] das circunstâncias externas que não podemos controlar e criarmos as nossas respostas e acções" (Carrilho, 2013: 10). A responsabilidade financeira é o produto de um trabalho sobre o Eu, que parte do autoconhecimento: sabermos onde pertencemos, de que forma somos produtivos, quais são os nossos valores e quais são as nossas fortalezas: "É aplicando as nossas forças que nos iremos diferenciar no local de trabalho e nas nossas vidas. Este trabalho de autoconhecimento deve ser realizado continuamente" (ibidem: 30 ). Estamos perante um "caminho de crescimento pessoal" (Zárate, 2008: 13). As finanças têm uma componente expressiva: falam publicamente acerca do núcleo distintivo de cada indivíduo, traduzem esse Eu e, simultaneamente, a sua gestão contribui para moldar a subjetividade da qual derivam.

O conhecimento financeiro é, por acréscimo, a condição prévia para desmascarar uma realidade, uma ordem social ou uma norma cultural que prejudicam o indivíduo. Cumpre uma função desmistificadora, atravessando o véu das aparências para aceder à verdade. Por isso, é necessário ir além do que é definido como convencional, normal ou possível. Uma formulação desta ideia pode ser encontrada na mudança de paradigma ou no desenvolvimento de uma nova visão sobre o dinheiro (Carrilho, 2013: 27). Essa nova visão teria um significado emancipatório: compreender os mecanismos monetários proporciona ao indivíduo a possibilidade de ser dono da sua vida. Ou, dito de um outro modo, abandonar a "corrida de ratos"; essa espiral sem sentido na qual a pessoa só consegue viver de ordenado em ordenado " $[\ldots]$ trabalhando para pagar contas, tal como um rato 
a correr sem parar numa roda, mas sem nunca sair do mesmo sítio" (ibidem: 38). Uma versão mais contundente defende o imperativo da mudança radical de visão relativa ao dinheiro, uma vez que "[...] quase tudo é mentira” (Zárate, 2008: 12). Será obrigatório esquecer as crenças financeiras, "tudo o que nos ensinaram desde pequeninos, e na universidade, e aquilo com que nos bombardeiam diariamente em todos os meios de comunicação" (ibidem). Há uma operação de rutura a realizar, "[...] veremos como funciona de verdade o mundo do dinheiro e as suas regras [...] vai ouvir ideias que chocarão frontalmente com tudo o que lhe foi incutido" (ibidem: 14). Se antes o objetivo era abandonar a "corrida dos ratos", agora a aceitação da verdade sobre o mundo do dinheiro deveria colocar a pessoa fora da "senda do borrego": primeiro ordenado, primeiras despesas, primeira casa, primeira hipoteca, aumento de ordenado, aumento das despesas, nova casa, mais empréstimos, mais endividamento. Para sair deste círculo vicioso, "temos de começar a pensar em criar ativos que gerem ativos, e não ganhar dinheiro para comprar passivos, que é o que a maioria das pessoas faz, e que financeiramente é uma estupidez" (ibidem: 43).

\subsection{O que fazer e como: o plano e a sua justificação}

Uma vez que o indivíduo conhece o marco social que explica a necessidade da autoajuda financeira e esclarece a sua própria situação em termos de finanças pessoais, chega o momento de desenvolver um plano de ação de acordo com as prescrições dos textos. Esse plano apresenta dois polos complementares que definem uma dupla estratégia destinada à consecução do sucesso financeiro da pessoa: a capitalização e a poupança.

O "poder da capitalização" (Almas e Madrinha, 2011: 108) baseia-se na acumulação de juros de forma continuada ao longo do tempo. Isto implica uma avaliação do risco que se deseja assumir (Ribeiro, 2011: 166), o que determina um perfil de investidor que vai desde "muito conservador" até "muito arriscado" (Almas e Madrinha, 2011: 114). Como tal, é recomendável começar a investir o mais cedo possível, já que isso "permite arriscar mais e conseguir uma taxa de rentabilidade potencial mais elevada [...] Podem dar-se ao luxo de registar perdas pontuais ao longo do tempo" (ibidem: 108) que serão compensadas com lucros futuros. Para isto, nem sequer é necessário ser um especialista: basta evitar "produtos estrambólicos", realizar uma escolha "fria e calculista", não pagar comissões de subscrição e não correr riscos cambiais (ibidem: 125-126).

O poder da capitalização está estritamente relacionado com o processo que leva a "inventar dinheiro", atitude inerente aos empreendedores: 
Estes são pessoas que estão sempre receptivas a novas ideias de negócio, a novas formas de capitalizar as suas poupanças. Garanto-vos que, incorporando este mind-set no vosso dia-a-dia, mais dinheiro vai entrar nas vossas vidas, e com muito pouco esforço associado. (Carrilho, 2013: 57)

Face à noção do indivíduo dependente que deseja segurança e um ordenado fixo, serão a inteligência e a integridade - alinhamento do desejo de lucro com os valores vitais - os fatores que garantem a independência financeira: não trabalhar nunca mais pelo dinheiro.

O "poder da poupança" remete para a implementação de um conjunto de restrições no orçamento familiar e pessoal que, ao tempo, permitem a constituição de um fundo para ser aplicado financeiramente: "E aqui o principal conselho é: poupe. Custe o que custar. Mesmo no caso das famílias em que os orçamentos estão tão apertados que o dinheiro quase não chega para as despesas mensais, a palavra de ordem tem de ser poupar" (Lourenço, 2009: 22). A partir deste apelo, o leque de sugestões e conselhos é comum entre as diferentes publicações: não fumar, não tomar o pequeno-almoço fora de casa, ir de transportes públicos, cortar no telemóvel, na televisão por cabo e na internet de alta velocidade (Almas e Madrinha, 2011: 129-136), utilizar lâmpadas ecológicas, fechar bem as torneiras, comprar marcas brancas (Lopes, 2009: 160), reduzir ou eliminar os cartões de crédito, alugar a casa de férias, trocar serviços entre vizinhos, ir à biblioteca, esperar até os filmes saírem em DVD (Carrilho, 2013: 76-82), não permitir às crianças intervirem na lista da compra, não comprar na fila de pagamento, vestir os filhos sem roupas de marca, não conduzir agressivamente, desligar os aparelhos em standby, isolar adequadamente a casa ou fechar bem a porta do frigorífico (Lourenço, 2009: 91).

Mas a poupança é sempre um investimento potencial e, por este motivo, o aforrador é também um investidor que não precisa de ser um perito. Bastam-lhe apenas uns conhecimentos básicos para guiar as suas decisões. Por exemplo, uma aproximação muito simples à lógica do Euribor permite que "[...] qualquer um de nós [possa] prever de forma razoavelmente segura o que se vai passar no mercado das taxas de juro: quando há riscos de subida da inflação, as taxas sobem; quando esses riscos se atenuam, as taxas descem" (ibidem: 133). O poder conjunto da capitalização e da poupança é o único caminho para garantir a satisfação material das necessidades individuais, quer no presente, quer no futuro. Do mesmo modo, também é a única forma de reduzir a incerteza face ao desconhecido. É um desígnio particular; uma obrigação que corresponde a cada indivíduo e que ninguém pode assumir por outro. Eis o porquê do plano. 
Se anteriormente essa incerteza não era sentida material e existencialmente devido ao sistema de providência social, agora a situação é bem diferente, facto que a LAF utiliza como justificação da pertinência dos seus conselhos: "Queremos que percebam que, enquanto a crise financeira actual é seguramente passageira, a bancarrota da Segurança Social é garantida" (Almas e Madrinha, 2011: 22). O fim do Fundo de Estabilização Financeira da Segurança Social terá lugar pouco depois de 2035 (ibidem: 47), uma data ainda longínqua quando comparada com outras previsões: "Com as incertezas sociais e económicas actuais, a forma de gestão e distribuição dos valores da Segurança Social e as evoluções demográficas, não sabemos sequer se teremos direito a reforma, ou sequer se a Segurança Social existirá daqui a 10 anos" (ibidem: 167). A única saída autenticamente responsável é a pessoa tomar as rédeas da sua vida sem esperar que as instituições venham em auxílio: "É que os primeiros e últimos responsáveis pelo nosso destino somos nós, não o Estado" (Lourenço, 2009: 21). A responsabilização e a sua lógica adquirem não só um significado material como garantia de necessidades futuras, mas também um significado expressivo: fala-nos da personalidade, daquilo que o indivíduo essencialmente é.

$\mathrm{O}$ aprofundamento desta lógica, através da qual a autorresponsabilização financeira é uma condição necessária para a liberdade financeira e, ainda, uma condição para uma emancipação autêntica das estruturas do mercado, encontra também o seu espaço na LAF. O individualismo utilitário, que reivindica o interesse como motor da ação humana, junto com o individualismo expressivo, que reivindica a subjetividade pessoal como núcleo da identidade (Bellah et al., 1989: 54-58, 394-395), aparecem ligados às estratégias de poupança-investimento e ao desenvolvimento do Eu num discurso formatado em moldes anarco-capitalistas (Brown, 1997; Streeter, 1999). Neste ponto, o posicionamento de Aitor Zárate é o melhor representante desta tendência. Para o autor interessa, sobretudo, a conduta discrepante e radicalmente diferente da conduta das massas: "Saia do caminho, fuja da linha recta e o êxito está garantido" (Zárate, 2008: 22). Simultaneamente, a discrepância conjuga-se com a não existência de segurança e de certeza, dois incentivos que conduzem à mudança constante: "[...] é melhor que assim seja já que nos fará sermos melhores" (ibidem: 39). A questão-chave é não fazer parte do "sistema", identificado com as contribuições para a Segurança Social, na qual não deseja participar. Quem contribui exclusivamente pelo facto de pensar que apenas quando é obrigado consegue não gastar hoje o dinheiro da reforma só mostra o seu "[...] nível de ignorância e a irresponsabilidade do sujeito [...] temos de pensar em valer-nos a nós próprios e não estar à espera que os outros se preocupem connosco" (ibidem: 128). 
Cada pessoa deve produzir as suas condições de segurança e certeza para hoje e amanhã. Além do investimento, e como recurso complementar, o indivíduo pode criar "estruturas fiscais", ou seja, um "mecanismo jurídico-legal que nos permite, utilizando as diferentes legislações do mundo, pagar menos impostos" (ibidem: 31), sendo que estes não devem ir além de $5 \%$ dos lucros. Evadir impostos é "pecado, delito", mas iludi-los "não é uma coisa nem outra” (ibidem: 166). Zárate, num dado momento do seu discurso, oferece alguns exemplos, vagos e pouco concretos: "[...] apenas mostrarei uma estrutura a título de exemplo [...] mas se for um rapaz esperto verá por onde vão os tiros" (ibidem: 166). Os exemplos são pistas para pagar impostos nos locais que seja mais favorável. Como tal, a Irlanda oferece boas oportunidades para escritores, a Dinamarca para royalties, a Holanda para sociedades intermediárias, o Mónaco facilita a residência fiscal e umas contas na Suíça são sempre um recurso a considerar (ibidem: 168).

\section{Racionalidade neoliberal e autoajuda financeira}

O discurso da LAF acerca da responsabilidade financeira e da conseguinte necessidade de corrigir as deficiências cognitivas e éticas dos indivíduos relativamente ao dinheiro não é inédito. Apresenta afinidades evidentes com o discurso de figuras políticas, dirigentes corporativos ou peritos em economia e finanças. Por outras palavras, certos argumentos e explicações sobre a crise e a situação portuguesa, juntamente com certos conselhos e recomendações para agir financeiramente, apresentam um carácter transversal quer dentro, quer fora do espaço da LAF. Uma pequena ilustração desta transversalidade são, por exemplo, as seguintes declarações recolhidas pela comunicação social e relacionadas com temas abordados anteriormente:

a) Pedro Seixas Vales, Presidente da Associação Portuguesa de Asseguradoras: "Cultura financeira tem de crescer em Portugal" (RTP, 31.10.2011).

b) Aníbal Cavaco Silva, Presidente da República Portuguesa: "Não podemos continuar a viver acima das nossas possibilidades" (Jornal de Notícias, 16.05.2011).

c) Vítor Bento, economista, Presidente da Sociedade Interbancária de Serviços (SIBS) e Conselheiro de Estado: "Economista [Vítor Bento] justifica a crise por portugueses terem feito vida de cigarra" (Jornal de Notícias, 26.05.2011).

d) João Salgueiro, Presidente da Associação Portuguesa de Bancos: "Portugueses culpados por endividamento" (Correio da Manhã, 25.09.2008) 
e) Carlos Costa, Governador do Banco de Portugal: "Os portugueses devem usar o crédito de forma mais responsável” (Diário de Notícias, 18.10.2012).

A transversalidade explica-se pelo facto de manifestarem o mesmo tipo de racionalidade política, nomeadamente uma racionalidade política neoliberal. O conceito de racionalidade política - devedor dos contributos de Michel Foucault sobre as relações entre o poder, o conhecimento e a subjetividade - tem sido desenvolvido e, sobretudo, empiricamente sustentado pelos estudos sobre a governamentalidade. A noção de racionalidade política designa os objetivos que são perseguidos no exercício do poder, os princípios teóricos que estruturam esses objetivos e a visão acerca da natureza dos sujeitos governados (Rose e Miller, 1992: 178; Marinis, 1999: 87-88). Sob esta perspetiva, o neoliberalismo não é tratado como uma filosofia política, uma ideologia ou uma modalidade específica de políticas públicas orientadas para o mercado. É, fundamentalmente, uma maneira de articular aqueles objetivos, princípios e conceções sobre os indivíduos de acordo com um vocabulário e um discurso específicos que concebem o sujeito governado como um sujeito autónomo e com iniciativa; iniciativa com a qual é possível economizar o exercício do poder (Ampudia de Haro, 2006: 66-67). Isto significa que os indivíduos terão de contribuir com a máxima intensidade e competência possíveis para o seu próprio autogoverno. No entanto, o indivíduo não é concebido como um corpo para disciplinar cuja resistência tem de ser vencida (Vázquez García, 2005: 178). Como apontávamos, conta-se com a autonomia dos governados para alinhá-la ou reconduzi-la de acordo com os objetivos de governo.

Quando afirmamos que a LAF é uma manifestação dessa racionalidade neoliberal, o que se pretende salientar é a sua condição de tecnologia de governo, isto é, o facto de ser um produto que produz um conhecimento e uma verdade específicas que legitimam uma intervenção sobre a conduta e a subjetividade pessoal. Mas que tipo de verdade e conhecimento gera a LAF?

a) Estabelece o tipo de deficiências cognitivas e éticas que impedem ou dificultam aos portugueses a sua autorregulação financeira.

b) Afirma que a agregação destas deficiências explica a crise que vive a sociedade. Tais deficiências individuais e essa incapacidade de autorregulação geram um resultado coletivo negativo: um país à beira da bancarrota.

c) Defende que a correção dessas deficiências passa pela aquisição de responsabilidade financeira e pela capacidade de autogoverno das finanças pessoais. Não se trata apenas de uma transformação num 
sentido técnico - ter conhecimentos financeiros - mas também num sentido pessoal-vital, ou seja, ser capaz de assumir a tarefa de governar-se a si próprio.

d) Declara essa tarefa como indispensável num tipo de enquadramento que apresenta o social e o coletivo sob uma perspetiva dupla. Por um lado, como fracasso e esgotamento, identificado com padrões insustentáveis e irracionais de consumo ou com o desaparecimento do Estado social. Por outro, como suspeita de manipulação paternalista identificada com uma cultura da dependência e de submissão perante as instituições do Estado-providência.

Em função desta verdade e deste conhecimento, a intervenção sobre a conduta e a subjetividade individuais tem um sentido concreto: o autogoverno financeiramente responsável mediante a poupança e o investimento. Quando o social é definido em termos de fracasso, esgotamento, manipulação, dependência ou dominação, resta apenas o autogoverno como saída responsável para confrontar o risco vital: "Lembrem-se que se não cuidarmos de nós, ninguém cuidará. É trabalho nosso aumentar o rendimento e criar riqueza" (Carrilho, 2013: 73). Mas não podemos esquecer que o autogoverno responsável exerce-se no mercado: através dos mercados financeiros e mediante o investimento e a capitalização o indivíduo adquire essa proteção contra os riscos e garante a satisfação das suas necessidades. Em definitivo, a LAF é mais uma ferramenta que o mercado coloca ao serviço da pessoa para gerir esses riscos através do mercado. Sendo assim, a incerteza que provocam esses riscos não é tal quando o indivíduo é financeiramente responsável. Ou, por outras palavras, ficar à mercê da incerteza não é mais do que um indício de irresponsabilidade individual.

Poderia argumentar-se que, no fundo, estamos simplesmente perante uma versão atualizada de um arquétipo de indivíduo guiado pelo princípio da prudência mais clássica, o que nos levaria de volta ao exemplo do Sr. Manuel, modelo de aforrador, ou da Avó Clara e a sua orçamentação rigorosa das despesas e das receitas da casa como meio para antecipar decisões financeiras (Lourenço, 2009: 23). Nesta formulação, a prudência liga-se à previsibilidade da evolução do rendimento, ao adiamento da gratificação e, mais importante, à aversão ao risco (Erturk et al., 2005). No entanto, é uma formulação que não se integra adequadamente no perfil de indivíduo que preconiza a racionalidade neoliberal em geral, e a LAF em particular. É mais apropriado falar em neoprudencialismo (O'Malley, 1996: 203), que vê o risco de forma positiva, como uma oportunidade que a pessoa pode gerir de forma consciente. Isto supõe uma escolha do nível de risco que se deseja aceitar; risco esse que nunca deveria ser uma desculpa para não se investir: 
Se o vosso maior objectivo for fugir às preocupações, então vão continuar pobres. A vida deve ser uma aventura e a preocupação é um princípio interno de prazer. Se puder escolher entre ser pobre e estar preocupado, eu escolho a preocupação. Só colocando parte do vosso dinheiro em risco, num risco relativamente controlado, é que podem fazê-lo crescer mais do que os que pouco têm. (Carrilho, 2013: 115)

\section{Conclusão}

Amiúde, os fenómenos económicos são apresentados como processos macroestruturais que se impõem pelo seu próprio peso. Ou, por outras palavras talvez menos exatas e mais gráficas, vencem sem necessitarem de convencer. Este artigo argumenta em sentido contrário: convencer é parte intrínseca do avanço da financeirização. $\mathrm{O}$ arquétipo humano que propõe a LAF pressupõe uma subjetividade específica adequada às necessidades e aos requisitos dos mercados financeiros. Deste modo, um material aparentemente insignificante ou anedótico adota o formato de ferramenta destinada à produção de um modo de entender a conduta e as emoções. O modelo de subjetividade que nasce da LAF lida sistematicamente com questões como o consumo e o endividamento, não só sob uma perspetiva técnica, mas também, e sobretudo, sob uma ótica de transformação pessoal. Essa transformação pessoal tem um objetivo fundamental: o autogoverno do indivíduo de acordo com um imperativo de responsabilidade individual. Uma vez que é anunciado o fim do sistema coletivo de providência e os riscos vitais são transferidos para cada pessoa, esta deve assumi-los como uma oportunidade criativa para garantir a sua própria segurança e combater a incerteza através dos recursos que oferece o mercado. A LAF descreve o tipo de subjetividade que há de ser desenvolvida para esta missão, mas também possui uma vocação normativa: essa subjetividade não é só funcionalmente adaptativa num contexto de financeirização, também é desejável. E é desejável porque a irresponsabilidade financeira é, precisamente, o fator que tem colocado a sociedade numa situação de crise. Ser irresponsável é não corrigir aquelas deficiências cognitivas e éticas que a LAF quer emendar. Por esse motivo, uma conduta deste cariz supõe um risco para a sociedade: a sua generalização situaria o país na bancarrota. Como tal, perfila-se uma noção de delinquência cognitiva (Walker, 2012) ligada a) à negação do processo de produção social do risco e da sua desigual distribuição em função da posição social; e b) à afirmação da individualização do risco e da mercantilização dos recursos para o controlar ou explorar financeiramente. A partir daqui, apenas resta o exercício dessa responsabilidade através dos meios que proporciona o mercado e nos contornos por ele definido; um suposto exercício de civismo que troca a participação na esfera pública pela dedicação privada aos assuntos financeiros. 


\section{Referências bibliográficas}

\section{Fontes primárias}

Almas, David; Madrinha, Joaquim (2011), Como salvar a minha reforma. Alfragide: Lua de Papel.

Carrilho, Pedro Queiroga (2013), O seu primeiro milhão. A versão anti-crise: como poupar e fazer crescer o seu dinheiro. Alfragide: Lua de Papel [2. ${ }^{\text {e ed.]. }}$

Lopes, Luís Ferreira (2009), Seja mais esperto do que a crise. Estratégias para organizar as suas finanças. Lisboa: A Esfera dos Livros [2. ${ }^{a}$ ed.].

Lourenço, Camilo (2009), Como esticar o salário e encurtar o mês. Alfragide: Livros d'Hoje. Ribeiro, José Manuel Malarmey (2011), Vacas magras, porcos gordos. Manual de boas práticas para conservar e fazer crescer o seu dinheiro. Lisboa: Babel.

Zárate, Aitor (2008), O que os ricos sabem e não contam. Manual de finanças para mudar a sua vida. Lisboa: A Esfera dos Livros.

\section{Fontes secundárias}

Aitken, Rob (2007), Performing Capital. Toward a Cultural Economy of Popular and Global Finance. New York: Palgrave Macmillan.

Alonso, Luis Enrique; Fernández Rodríguez, Carlos Jesús (orgs.) (2012), La financiarización de las relaciones salariales. Una perspectiva internacional. Madrid: Los Libros de la Catarata.

Ampudia de Haro, Fernando (2006), "Administrar el yo: literatura de autoayuda y gestión del comportamiento y los afectos”, Revista Española de Investigaciones Sociológicas (REIS), 113, 49-75.

Ampudia de Haro, Fernando (2010), "El logro del éxito: la dimensión social de la literatura de autoayuda", Revista Española de Sociología, 13, 11-30.

Ampudia de Haro, Fernando (2011), "Gestão, desenvolvimento e êxito: Sociogénese da literatura de auto-ajuda em Portugal”, Revista Crítica de Ciências Sociais, 94, 41-61.

Ampudia de Haro (2014), "El gobierno de la bancarrota: racionalidad neoliberal y educación financiera en Portugal”, Papers. Revista de Sociologia (no prelo).

Bay, Charlotte; Catasús, Bino; Johed, Gustav (2012), "Situating Financial Literacy", Critical Perspectives on Accounting (no prelo).

Bellah, Robert; Madsen, Richard; Sullivan, William M.; Swidler, Ann; Tipton, Steven M. (1989), Hábitos del corazón. Madrid: Alianza Editorial.

Brown, Susan L. (1997), "The Free-market as Salvation from Government: The Anarcho-capitalist View", in James G. Carrier (org.), Meanings of the Market. The Free Market in Western Culture. Oxford/New York: Berg, 99-128.

CNSF - Conselho Nacional de Supervisores Financeiros (2011), Plano Nacional de Formação Financeira (2011-2015). Lisboa: Banco de Portugal, Serviço de Edições e Publicações. Consultado a 21.11.2013, em http://www.cmvm.pt/CMVM/ Coopera \%C3\%A7\%C3\%A3o\%20Nacional/Conselho\%20Nacional\%20de \%20 
Supervisores \%20Financeiros/Documents/Plano \%20Nacional\%20de \% 20 Forma \%C3\%A7\%C3\%A30\%20Financeira.pdf.

Clark, Gordon; Thrift, Nigel; Tickett, Adam (2004), "Performing Finance: the Industry, the Media and its Image”, Review of International Political Economy, 11(2), 289-310.

Epstein, Gerald A. (org.) (2005), Financialization and the World Economy. Cheltenham, Camberley, Northampton, MA: Edward Elgar Publishing.

Erturk, Ismail; Froud, Julie; Solari, Stefano; Williams, Karel (2005), “The Reinvention of Prudence: Household Savings, Financialisation and Forms of Capitalism”, CRESC Working Paper Series, WPaper 11. Consultado a 22.11.2013, em http://www.cresc. ac.uk/publications/the-reinvention-of-prudence-household-savings-financialisation-and-forms-of-capitalism.

Erturk, Ismail; Leaver, Adam; Froud, Julie; Williams, Karel; Johal, Sukhdev (2007), "The Democratization of Finance? Promises, Outcomes and Conditions", Review of International Political Economy, 14(4), 553-575.

Fridman, Daniel (2010), "From Rats to Riches: Game Playing and the Production of the Capitalist Self”, Qualitative Sociology, 33(4), 423-446.

Harrington, Brooke (2008), Pop Finance. Investments Clubs and the New Investor Populism. Princeton: Princeton University Press.

Heilbron, Johan (2005), “Taking a Stock: toward a Historical Sociology of Financial Regimes", Economic Sociology. The European Electronic Newsletter, 7(1), 3-17. Consultado a 22.11.2013, em http://econsoc.mpifg.de/archive/esoct05.pdf.

Ibáñez, Jesús (1985), Del algoritmo al sujeto: perspectivas de la investigación social. Madrid: Siglo XXI.

Martínez González-Tablas, Ángel (2012), "Financiarización, economía y sociedad", in Luis Enrique Alonso; Carlos J. Fernández Rodríguez (orgs.), La financiarización de las relaciones salariales. Una perspectiva internacional. Madrid: Los libros de la catarata, 27-43.

Langley, Paul (2007), "Uncertain Subjects of Anglo-American Financialization”, Cultural Critique, 65, 67-91.

Leyshon, Andrew; Thrift, Nigel (2007), "The Capitalization of Almost Everything. The Future of Finance and Capitalism”, Theory, Culture E Society, 24(7-8), 97-115. Marinis, Pablo de (1999), "Gobierno, gubernamentalidad, Foucault y los anglofoucaltianos (O un ensayo sobre la racionalidad política del neoliberalismo)”, in Ramón Ramos; Fernando García (orgs.), Globalización, riesgo, reflexividad. Tres temas de la teoría social contemporánea. Madrid: CIS, 73-103.

Martin, Randy (2002), Financialization of Daily Life. Philadelphia: Temple University Press.

Medialdea García, Bibiana; Sanabria Martín, Antonio (2013), "La financiarización de la economía mundial: hacia una caracterización”, Revista de Economía Mundial, 33, $195-227$. 
Miller, Peter; Rose, Nikolas (1990), “Governing Economic Life”, Economy and Society, 19(1), 1-31.

O’Malley, Pat (1996), "Risk and Responsibility", in Andrew Barry; Thomas Osborne; Nikolas Rose (orgs.), The Foucault Effect. Studies in Governmentality. London: Harvester Wheatsheaf, 189-207.

Papalini, Vanina (2008), La formation de la subjectivité dans la culture contemporaine: Le cas des libres de bien-être. Tese de Doutoramento: Departamento de Comunicação, Universidade de Paris 8.

Papalini, Vanina (2010), "Libros de autoayuda: Biblioterapia para la felicidad", Athenea Digital. Revista de Pensamiento e Investigación Social, 19, 147-169. Consultado a 22.11.2013, em http://atheneadigital.net/issue/view/21.

Papalini, Vanina (2013), "Recetas para sobrevivir a las exigencias del neocapitalismo (o de cómo la autoayuda se volvió parte de nuestro sentido común)", Nueva Sociedad, 245, 163-177.

Preda, Alex (2005), “The Investor as a Cultural Figure of Global Capitalism”, in Karin Knorr-Cetina; Alex Preda (orgs.), The Sociology of Financial Markets. Oxford: Oxford University Press.

Rose, Nikolas; Miller, Peter (1992), "Political Power beyond the State: Problematics of Government", The British Journal of Sociology, 43(2), 173-205.

Ruesga, Santos M. (2012), "La financiarización de las relaciones laborales”, in Luis Enrique Alonso e Carlos J. Fernández Rodríguez (orgs.), La financiarización de las relaciones salariales. Una perspectiva internacional. Madrid: Los libros de la catarata. Shiller, Robert J. (2007), "Risk Management for Households. The Democratization of Finance”, palestra apresentada na Sixth Annual Bank for International Settlements Conference 'Financial System and Macroeconomic Resilience', decorrida em Brunnen, Suiça, de 18 a 19 de junho. Consultado a 22.11.2013, em https://www.bis. org/events/brunnen07/shillerpap.pdf.

Smiles, Samuel (1908), Self-Help. With Illustrations of Conduct and Perseverance. London: John Murray [ed. orig.: 1875].

Streeter, T. (1999), "That Deep Romantic Chasm: Libertarianism, Neoliberalism and the Computer Culture", in Andrew Calabrese; Jean-Claude Burgelman (orgs.), Communication, Citizenship and Social Policy. Re-thinking the Limits of the Welfare State. Lanham, MD: Rowman \& Littlefield, 49-64.

Vázquez García, Francisco (2005), Tras la autoestima. Variaciones sobre el yo expresivo en la modernidad tardía. San Sebastián: Tercera Prensa.

Walker, Carl (2012), "Cognitive Delinquency and Techniques of Governmentality: Neoliberal Constructions of Financial Inadequacy in the UK", Journal of Community E Applied Social Pschycology, 22(6), 533-538. 
